\title{
Portal hypertension resulting from splenic arteriovenous fistulae
}

\author{
GEORGE W. JOHNSTON AND JAMES B. GIBSON \\ From the Department of Surgery, Queen's University, Belfast
}

EDITORIAL SYNOPSIS Splenic arteriovenous fistula is one of the rarer causes of splenomegaly and of portal hypertension. The present paper describes three well-documented cases, one of which was diagnosed by aortography. The literature is reviewed carefully.

Portal hypertension is commonly due to obstruction to portal blood flow either within the liver as in cirrhosis, or within the portal vein, as from thrombosis. In recent years, however, reports have multiplied of portal hypertension in the absence of both intrahepatic and extrahepatic obstruction (Rousselot, 1940; Whipple, 1945; Hallenbeck and Shocket, 1957; Tisdale, Klatstin, and Glenn, 1959; Leather, 1961 ; Imanaga, Yamamoto, and Kuroyanagi 1962; Polish, Christie, Cohen, and Sullivan, 1962; Valdoni, 1963; Siderys and Vellios, 1964; Turnberg, 1964), and interest has been directed to other ways in which portal hypertension might be brought about. Shunts between the portal-venous and the arterial systems have been postulated in some such cases but rarely demonstrated. The following three cases show that such shunts in the portal-venous bed may cause all the phenomena of portal hypertension or may have only limited manifestations. Fistulae between the splenic artery and vein were found in the splenic pedicles in all three cases and oesophageal varices were demonstrated in two of them.

\section{CASE REPORTS}

CASE 1 A woman (E.McG.), aged 35, was admitted to hospital with haematemesis and splenomegaly. For two years previously she had complained of nausea and lassitude. Liver function tests were normal. Barium swallow and oesophagoscopy confirmed the presence of oesophageal varices.

At operation the portal pressure was $290 \mathrm{~mm}$. of saline. The splenic vein contained multiple saccular distentions and varices. The splenic artery was tortuous and dilated and had a marked thrill, which was transmitted to the vein. A diagnosis of splenic arteriovenous aneurysm was made and splenectomy performed. The post-splenectomy portal pressure was $190 \mathrm{~mm}$. of saline. Unfortunately the patient developed a massive collapse of the right lung, and pneumonia post-operatively. She then had a further haematemesis and died eight days after surgery.
Pathology confirmed the diagnosis of splenic arteriovenous aneurysm.

CASE 2 A woman (F.W.), 44 years of age, was admitted to hospital for investigation of essential hypertension and headaches. The history included 13 pregnancies. Blood pressure was $185 / 125 \mathrm{~mm}$. Hg. The spleen was enlarged to $5 \mathrm{~cm}$. below the costal margin. A continuous bruit, maximal posteriorly, was heard over the splenic area. Liver function tests were normal. Barium swallow did not show any varices. An arteriogram confirmed the diagnosis of a splenic arteriovenous fistula (Fig. 1).

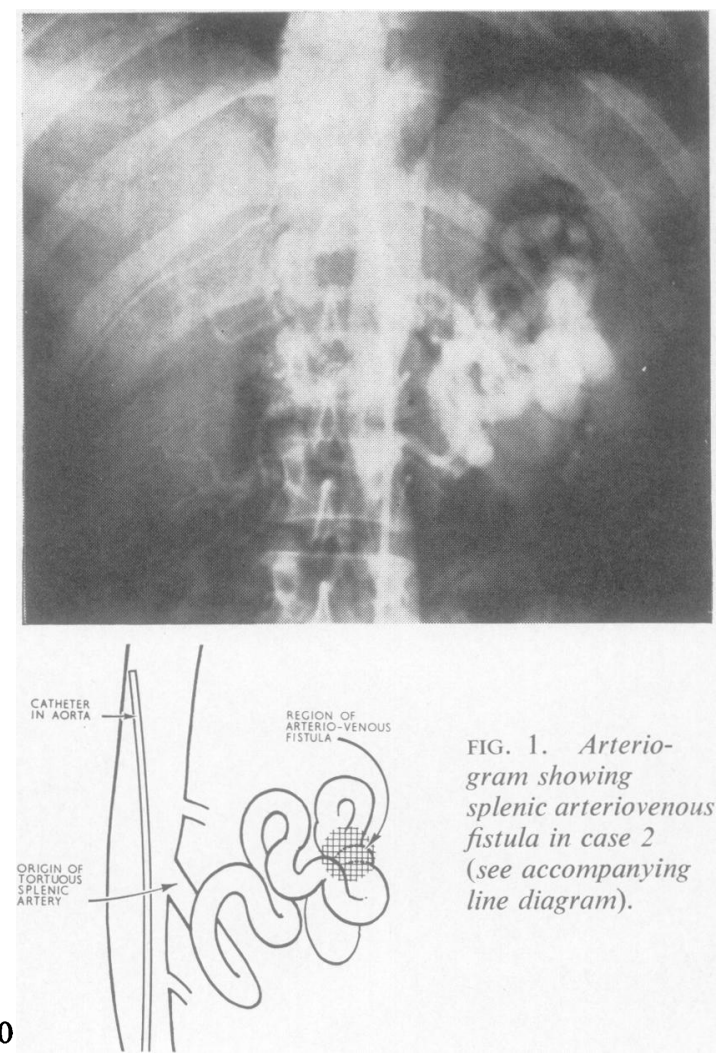


At operation the splenic artery and vein were both markedly dilated and gave rise to a thrill. Splenectomy was performed and the surgical specimen included the arteriovenous fistula close to the hilum of the spleen. The post-operative course was uneventful and the patient feels well two and a half years later, though essential hypertension remains.

CASE 3 A man (J.C.) first presented at hospital when 82 years old with pain in the left hypochondrium. The spleen was enlarged. Liver function tests were normal. Barium swallow revealed oesophageal varices. Splenectomy was performed and the post-operative course was uneventful. He remains well one year later. The spleen weighed $1,750 \mathrm{~g}$. and showed the features of fibroadenia with siderotic nodules; a fistula in the splenic pedicle connected the main splenic artery to a major radicle of the splenic vein (Fig. 2).

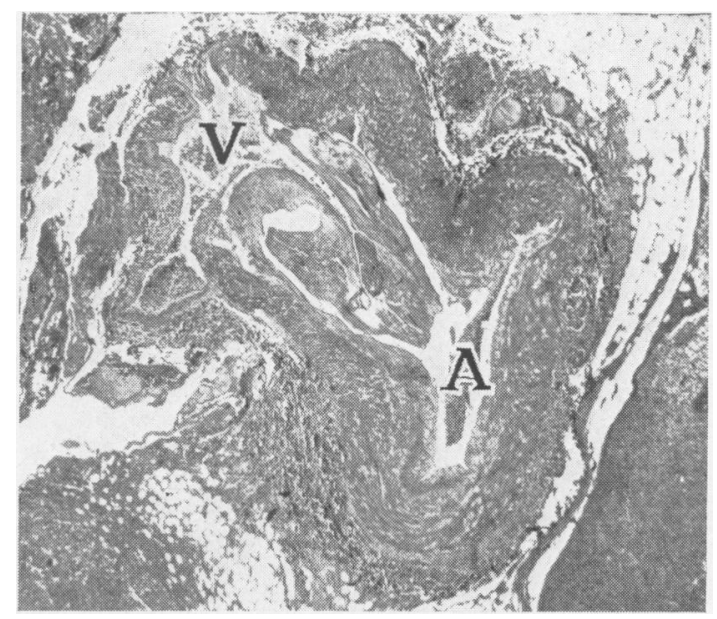

FIG. 2. Photomicrograph showing splenic arteriovenous fistula in case 3. The lumen of the splenic artery is marked with $A$ and the lumen of the vein with V. Picro-Mallory stain $\times 25$.

\section{COMMENT}

Arteriovenous fistulae in the splenic pedicle are rare, and Murray, Thal, and Greenspan (1960) found only eight cases in the literature and added one of their own, The fistulae are probably acquired lesions in most instances, arising sometimes from trauma, as in the case of Cassel, Spittel, Ellis, and Bruwer (1957) and probably also from spontaneous rupture of aneurysms of the splenic artery. The fistulae are commoner in women than in men. Eight out of the nine cases mentioned by Murray et al. (1960) and two of our three cases were women. It is relevant that splenic aneurysms rupture spontaneously most often during pregnancy, for 13 pregnancies are recorded in our case 2. Aneurysms are common and often silent, and not in themselves regularly associated with either arterial or portal venous hypertension. Bedford and Lodge (1960) found medial degeneration the commonest cause.

The fistula in case 2 was diagnosed pre-operatively by the presence of a bruit over an enlarged spleen and a positive arteriogram. Pre-operative diagnoses on the same findings were made by Stener (1955) and Cassel et al. (1957). It is important to diagnose this cause of portal hypertension before operation because portacaval shunt is not curative and may even endanger the patient unnecessarily by throwing an increased strain on the heart and by exposing him to the risk of portal systemic encephalopathy. Simple splenectomy is curative and with preoperative diagnosis the prognosis is usually good.

The splenic-venous pressure was elevated sufficiently in all our three cases to cause splenomegaly but varices were demonstrated in the oesophagus in only two of them. It appears that a considerable leak of arterial blood into the venous system is necessary to bring about the full picture of portal hypertension. The effect of a small arteriovenous fistula is likely to be relatively slight, since according to Poiseuille's law the volume of flow through a tube is related to the fourth power of the radius of the tube. Fistula between the main portal vein and the hepatic artery can lead to portal hypertension with splenomegaly and oesophageal varices. The condition was first reported by Sachs in 1892. Forster and Sandblom (1961) collected reports of only eight such cases, including one of their own. Experiments on dogs are not helpful in deciding the importance of arteriovenous fistulae in portal hypertension, for natural portal-systemic anastomoses are so efficient in this species that oesophageal varices do not tend to develop. Schilling and McKee (1953) found that even large fistulae between the hepatic artery and the portal vein failed to produce any consistent rise in portal venous pressure in their dogs. Tamiya and Thal (1960), however, succeeded in producing oesophageal varices and portal hypertension in dogs by creating splenic arteriovenous fistulae after the removal of the extra-oesophageal circulation.

These observations suggest that in the absence of any form of obstruction to the portal vein, an arteriovenous shunt of considerable volume is necessary to cause portal hypertension. It is possible that many small shunts may achieve this effect in cirrhosis as suggested by Herrick in 1907. Injection techniques have shown arteriovenous fistulae (Popper, Elias, and Petty, 1952) and increased intercommunication between hepatic arteries and portal veins within the cirrhotic liver (Hales, Allan, and Hall, 1959). Retrograde blood flow in the cirrhotic liver has been demonstrated after porta- 
caval shunt (Warren and Muller, 1959), and Evans blue dye injected into the hepatic artery rapidly appears in the portal vein (Longmire, 1957). It is not clear, however, how important this mechanism is in causing portal hypertension in cirrhosis.

When portal hypertension is encountered in the absence of cirrhosis or any other cause of portal venous obstruction, increased portal blood flow from a lesion such as arteriovenous fistula deserves consideration. Tisdale et al. (1959) reported four patients with portal hypertension and haematemeses from oesophageal varices in whom no obstructive lesion was demonstrated either within the liver or in the portal vein after careful investigation. In a useful discussion they drew attention to the importance of an increased flow of blood in causing hypertension in the portal vein, and suggested that such increases might be caused by undetected structural alterations such as the opening up of arteriovenous shunts in the gastrointestinal tract. According to Edmunds and West (1962), the action of vasopressin in lowering the portal venous pressure may be due partly to the closing of such shunts, and Womack and Peters (1957) deduced, from experimental studies and measurements of portal venous oxygen tension, that shunts of this sort exist in the submucosa of the stomach in the dog. The same workers also found the venous blood in oesophageal varices in man to be highly oxygenated (Peters and Womack, 1961). It would appear that if such shunts are of importance in man they must be either numerous or unexpectedly large. It is possible that mechanisms of this sort may play a part in causing portal hypertension in tropical splenomegaly. In temperate climates obstruction to the vein in one form or another is undoubtedly the only frequent cause of portal hypertension. In obscure cases where the portal vein stem is patent and cirrhosis is absent, inconspicuous obstructions may sometimes be found in the intrahepatic branches of the portal vein (Gibson, Johnston, Fulton, and Rodgers, 1965). Nevertheless experience with cases of arteriovenous fistula such as those reported here shows that increased portal venous flow can bring about by itself the manifestations of portal hypertension.

\section{SUMMARY}

Three cases of splenic arteriovenous fistulae are cited. One was diagnosed pre-operatively. All were treated by splenectomy alone. The relationship of arteriovenous fistulae to portal hypertension is discussed.

We wish to thank Dr. J. F. Pantridge for permission to publish case 2, Mr. H. Dales for permission to publish case 3, and Professor J. H. Biggart for permission to make use of the histological section of case 3 . We also thank Mr. R. Wood and Mr. D Mehaffey for the illustrations.

\section{REFERENCES}

Bedford, P. D., and Lodge, B. (1960). Aneurysm of the splenic artery. Gut, 1, 312-320.

Cassel, W. G., Spittel, J. A., Jr., Ellis, F. H., Jr., and Bruwer, A. J. (1957). Arteriovenous fistula of the splenic vessels producing ascites. Circulation, 16, 1077-1083.

Edmunds, R., and West, J. P. (1962). A study of the effect of vasopressin on portal and systemic blood pressures. Surg. Gynec. Obstet., 114, 458-462.

Foster, J. H., and Sandblom, P. (1961). Portal hypertension secondary to an hepato-portal arteriovenous fistula. Ann. Surg., 154, 300-304.

Gibson, J. B., Johnston, G. W., Fulton, T. T., and Rodgers, H. W. (1965). Extrahepatic portal-venous obstruction. Brit. J. Surg., 52, 129-139.

Hales, M. R., Allan, J. S., and Hall, E. M. (1959). Injection-corrosion studies of normal and cirrhotic livers. Amer. J. Path., 35, 909-941.

Hallenbeck, G. A., and Shocket, E. (1957). An evaluation of portacaval shunts for portal hypertension. Surg. Gynec. Obstet., 105, 40-60.

Herrick, F. C. (1907). An experimental study into the cause of the increased portal pressure in portal cirrhosis. J. exp. Med., 9 93-104.

Imanaga, H., Yamamoto, S., and Kuroyanagi, Y. (1962). Surgical treatment of portal hypertension according to state of intrahepatic circulation. Ann. Surg., 155, 42-50.

Leather, H. M. (1961). Portal hypertension and gross splenomegaly in Uganda. Brit. med. J., 1, 15-18.

Longmire, W. P. (1957). In discussion of paper by Taylor, F. W., Experimental portal hypertension. Ann. Surg., 146, 683-690.

Murray, M. J., Thal, A. P., and Greenspan, R. (1960). Splenic arteriovenous fistulas as a cause of portal hypertension. Amer. J. Med., 29, 849-856.

Peters, R. M., and Womack, N. A. (1961). Surgery of vascular distortions in cirrhosis of the liver. Ann. Surg., 154, 432-445.

Polish, E., Christie, J., Cohen, A., and Sullivan, B., Jr. (1962). Idiopathic presinusoidal portal hypertension (Banti's syndrome). Ann. intern. Med., 56, 624-627.

Popper, H., Elias, H., and Petty, D. E. (1952). Vascular pattern of the cirrhotic liver. Amer. J. clin. Path., 22, 717-729.

Rousselot, L. M. (1940). The late phase of congestive splenomegaly (Banti's syndrome) with hematemesis but without cirrhosis of the liver. Further observations on the etiology of Banti's syndrome and the effect on prognosis of certain variations in portal venous pattern. Surgery, 8, 34-42.

Sachs, R. (1892). Zur Casuistik der Gefässerkrankungen. Dtsch. med. Wschr., 18, 443-447. Quoted by Foster, J. H., and Sandblom, P. (1961).

Schilling, J. A., and McKee, F. W. (1953). Late follow-up on experimental hepatic-portal arterio-venous fistulae. Surg. Forum, 4, 392-397.

Siderys, H., and Vellios, F. (1964). Portal hypertension without cirrhosis or extrahepatic obstruction. Amer. J. Surg., 108, 785-789.

Stener, B. (1955). Arterio-venous shunt in the spleen diagnosed before operation. Acta chir. scand., 108, 344-350.

Tamiya, T., and Thal, A. P. (1960). Esophageal varices produced experimentally in the dog. Surg. Gynec. Obstet., 111, 147-154.

Tisdale, W. A., Klatskin, G., and Glenn, W. W. L. (1959). Portal hypertension and bleeding esophageal varices. Their occurrence in the absence of both intrahepatic and extrahepatic obstruc tion of the portal vein. New Engl. J. Med., 261, 209-218.

Turnberg, L. (1964). Portal hypertension in the absence of cirrhosis or obstruction of the portal vein. Postgrad. med. J., 40, 39-42.

Valdoni, P. (1963). Portal hypertension. Personal experience of the surgical treatment. Proc. roy. Soc. Med., 56, 261-263.

Warren, W. D., and Muller, W. H., Jr. (1959). A clarification of some hemodynamic changes in cirrhosis and their surgical significance. Ann. Surg., 150, 413-127.

Whipple, A. O. (1945). The problem of portal hypertension in relation to hepatosplenopathies. Ibid., 122, 449-475.

Womack, N. A., and Peters, R. M. (1957). An investigation of the relationship between portal venous pressure and inferior vena caval and portal venous oxygen saturation. Ibid., 146, 691-699. 